\title{
High Temperature Annealing of Twin-Roll Cast Al-Li-Based Alloy Studied by In- situ SEM and STEM
}

Miroslav Cieslar $^{1}$, Rostislav Králík ${ }^{1}$, Lucia Bajtošová ${ }^{1}$, Barbora Křivskáa ${ }^{1}$, Michal Hájek ${ }^{1}$, Sára Belejová $^{1}$, Olexandr Grydin ${ }^{2}$, Mykhailo Stolbchenko², and Mirko Schaper ${ }^{2}$

${ }^{1}$ Faculty of Mathematics and Physics, Charles University, Ke Karlovu 3,12116 Prague, Czech Republic.

${ }^{2}$ Chair of Materials Science, Paderborn University, Warburger Str. 100, 33098 Paderborn, Germany.

Recently, Al-Li alloys have re-gained attention for their use in weight and stiffness-critical structures used in aircraft and aerospace applications because they exhibit better properties (low density and high specific strength) than commercial Al alloys [1,2]. The solidification range of aluminum alloys under the metastable cooling conditions varies from $10 \mathrm{~K}$ for A199.5\% to more than $160 \mathrm{~K}$ for high-alloyed Al-Zn$\mathrm{Mg}$ alloys. This feature makes achievement of a homogeneous distribution of alloying elements difficult in high-alloyed aluminum manufactured by means of conventional casting processes, such as DC- or mold casting [3]. The cooling rate during TRC can reach $10^{3} \mathrm{~K} / \mathrm{s}$, which is much higher than in other casting processes [4]. The high solidification rate enables formation of a fine dendritic microstructure with fine intermetallic particles. Thus, a relatively high content of alloying elements in high-alloyed alloys can be nearly homogeneously distributed in the strip without a significant macroscopic gradient over its thickness, which is unavoidable in DC-cast ingots.

However, a formation of $\mathrm{Cu}$ and Fe-containing primary particles was observed in an Al-Li-based alloy of a third generation containing $3.71 \% \mathrm{Cu}, 0.91 \% \mathrm{Li}, 0.31 \% \mathrm{Mg}, 0.15 \% \mathrm{Zr}$ and $0.05 \% \mathrm{Fe}$. Their dissolution and transformation simulating a homogenization annealing was performed in-situ in TEM during isochronal annealing with a step $20 \mathrm{~K} / 5$ min using STEM BF and SEM SE contrasts in a JEOL JEM2000 FX electron microscope. A thin foil prepared by a standard electrolytic twin-jet polishing of the foil in a $30 \%$ nitric acid in methanol at $-20{ }^{\circ} \mathrm{C}$ transparent for electrons accelerated by $200 \mathrm{kV}$ was heated in a heating TEM stage. The transformation of primary $\mathrm{Al}_{7} \mathrm{Cu}_{2} \mathrm{Fe}$ into two secondary phase particles $\left(\mathrm{Al}_{5} \mathrm{CuLi}_{3}\right.$ and $\mathrm{Al}_{13} \mathrm{Fe}_{3}$ ) was studied. Signals from the two detectors are sensitive to different processes. While the signal from the SE detector is sensitive to the surface diffusion processes occurring during the high temperature annealing (Fig. 1), the STEM BF image detects rather changes in the morphology of the primary and transformed phases (Fig. 2) - both figures show the same area at different annealing temperatures [5].

References:

[1] R Rioja and J Liu, Metall. Mater. Trans. A 43 (2012), p. 3325.

[2] E Lavernia, T Srivatsan and JF Mohamed, J. Mater. Sci. 25 (1990), p. 1137.

[3] L Wang et al, Mater. Sci. Eng. A 652 (2016), p. 221.

[4] NS Barekar and BK Dhindaw, Mater. Manuf. Process. 29 (2014), p. 651.

[5] Authors would like to acknowledge the support of the Czech Science Foundation under the project 20-19170S. 

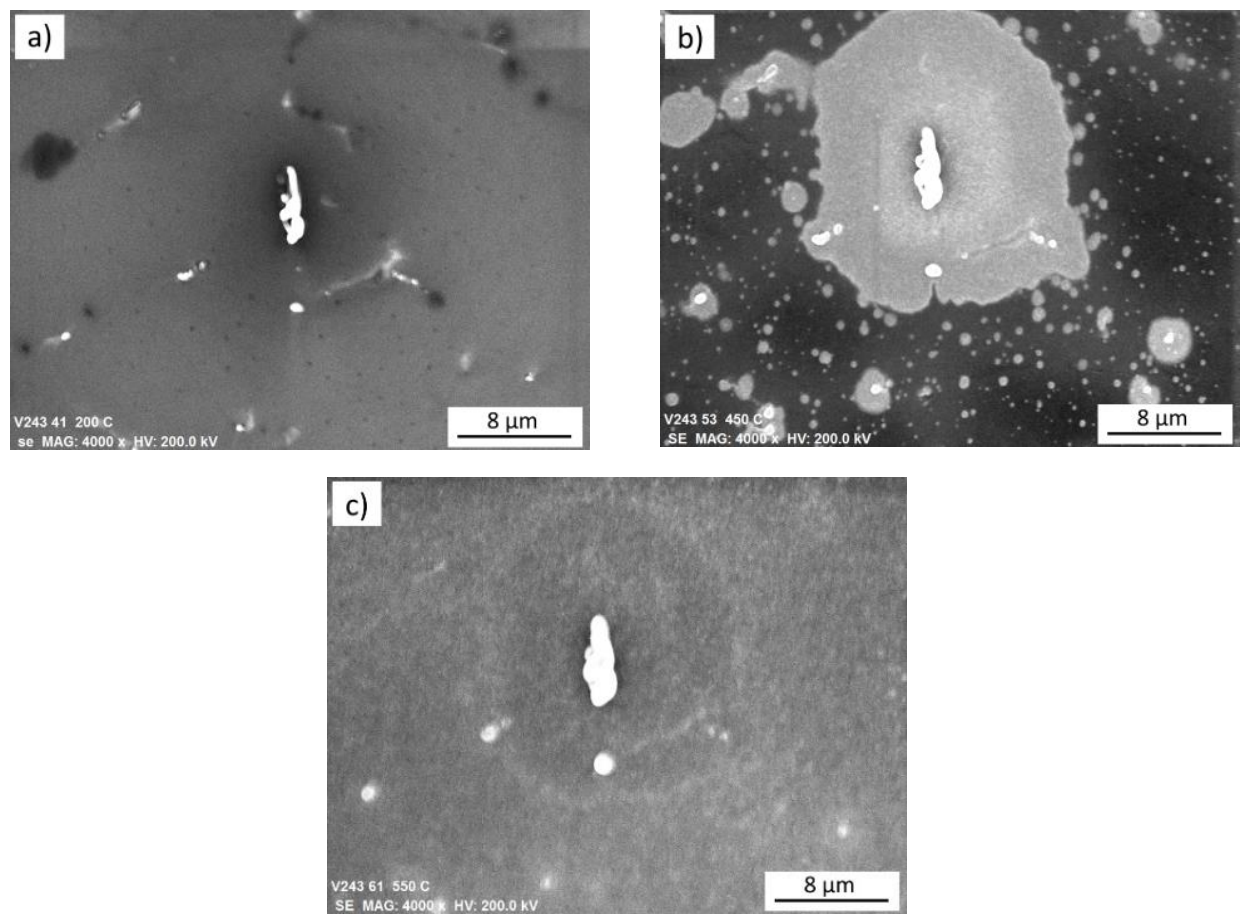

Figure 1. Evolution of the TRC structure studied by SE detector: a) $240{ }^{\circ} \mathrm{C}$, b) $450{ }^{\circ} \mathrm{C}$, and c) $550{ }^{\circ} \mathrm{C}$
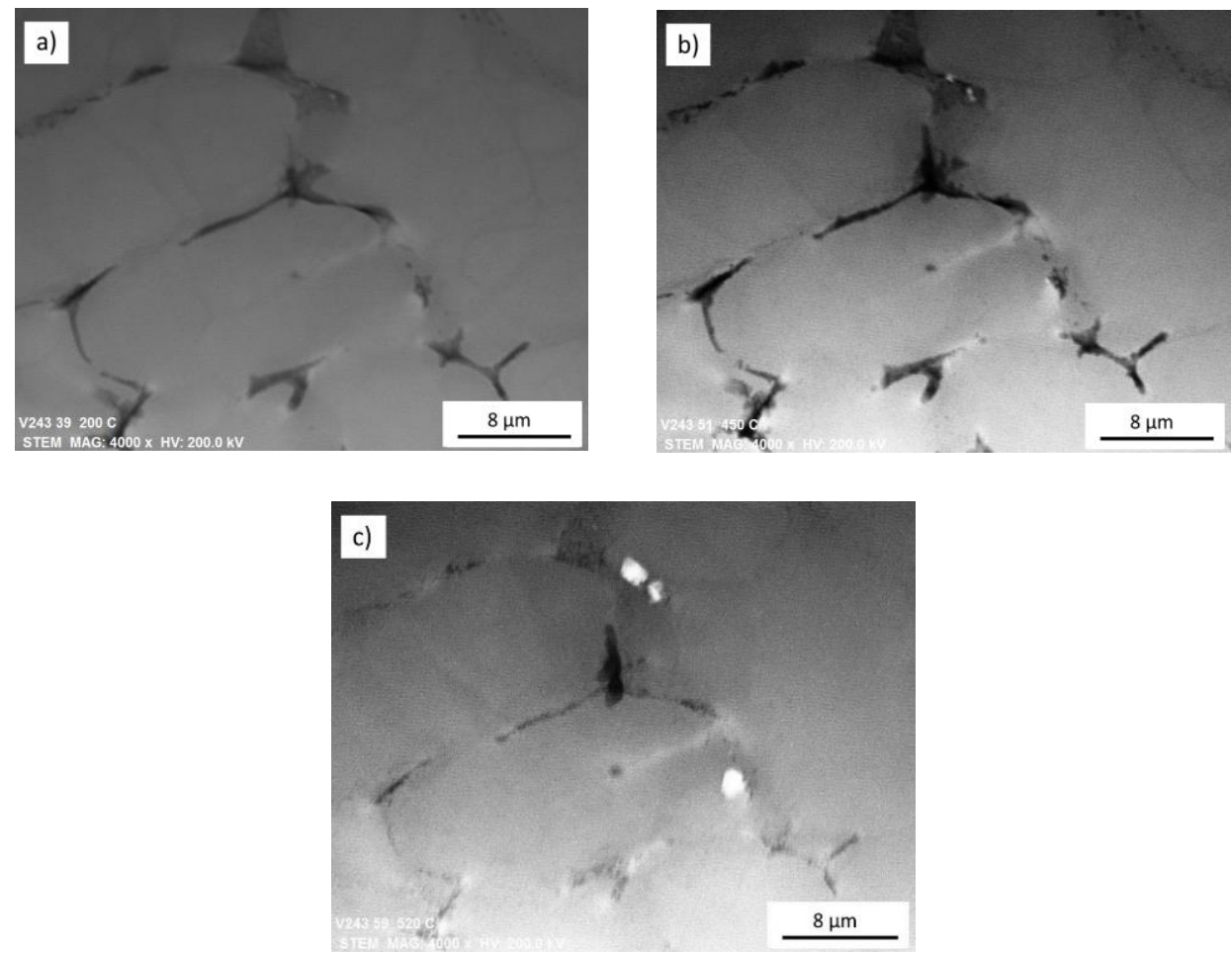

Figure 2. Evolution of the TRC structure from Fig. 1 studied by STEM BF detector: a) $240{ }^{\circ} \mathrm{C}$, b) $450{ }^{\circ} \mathrm{C}$, and c) $550{ }^{\circ} \mathrm{C}$. 